\section{Increased Throughput of BAC/PAC Insert Size Determinations by Stacking Gels during Pulsed-Field Gel Electrophoresis}

BioTechniques 34:718-720 (April 2003)

We recently reported the construction of a BAC/PAC-contig on the porcine chromosome $6 \mathrm{q} 1.2$ (1). For the construction of high-resolution physical maps, the insert size of clones within clone contigs is usually determined by pulsed-field gel electrophoresis (2). The information about clone sizes is essential to extend contigs by a chromosome walking strategy, where end sequences of protruding clones are used to find neighboring clones.

We have developed a method to increase the throughput for determining the insert size of BAC and PAC clones using pulsed-field gel electrophoresis. The method consists of stacking up to four agarose gels on top of each other during electrophoresis. This way, four times as many samples can be analyzed in one experiment compared to standard pulsed-field gel electrophoresis.

BAC and PAC DNAs were isolated using a Plasmid Midi Kit from Qiagen (Hilden, Germany), according to the manufacturer's protocol. Approximate-

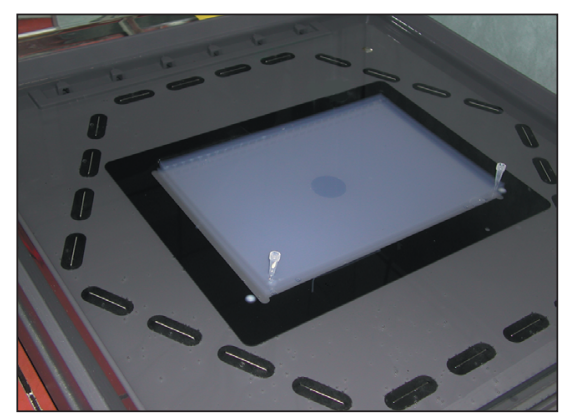

Figure 1. Assembly of the pulsed-field gel electrophoresis using two gels. After the samples of the bottom gel have been loaded, the top gel can be carefully placed on top of the bottom gel. To ensure that the gels cannot move during the run, they are fixed with two thin pipet tips at the front edges. Gels are completely covered with the running buffer $0.4 \times$ TBE. Up to four gels stacked on top of each other have been successfully run using these conditions.
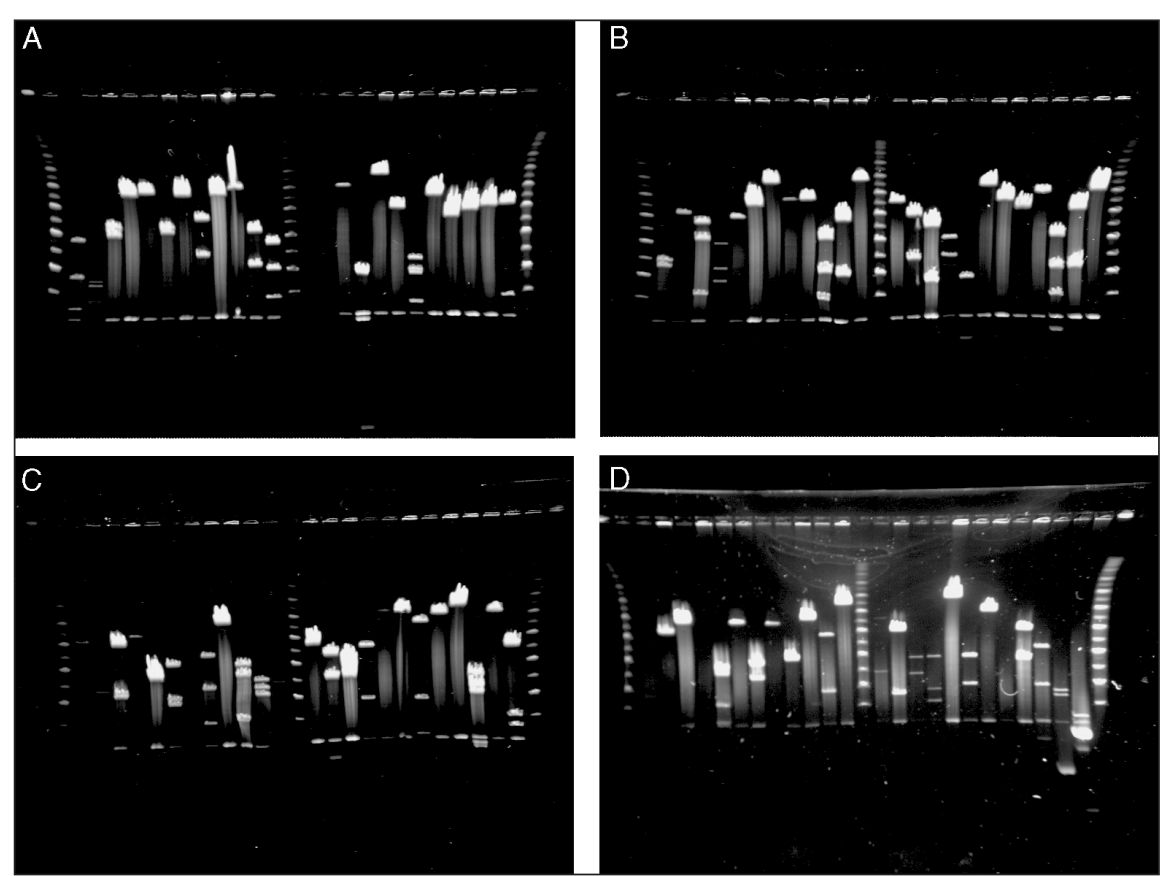

Figure 2. Results of a pulsed-field electrophoresis with four stacked gels. 96 BAC DNAs were digested with NotI and applied to the gels. The MidRange PFG Marker II was used as marker for BAC insert size determination. The marker was loaded in the middle and on both sides of the gels so that smiling effects could be corrected. Gels are shown from (A) bottom to (D) top.

ly 80 ng BAC/PAC DNA were digested with 2 U Not I in a total volume of 15 $\mu \mathrm{L}$ for at least $1 \mathrm{~h}$ at $37^{\circ} \mathrm{C}$. DNA was analyzed after digestion by using a CHEF-DR ${ }^{\circledR}$ III system (Bio-Rad Laboratories, Munich, Germany) with the following parameters: $1 \%$ agarose gel $(210 \times 139 \times 4 \mathrm{~mm})$ in $0.4 \times \mathrm{TBE}(36$ $\mathrm{mM}$ Tris, $\mathrm{pH} 8.3,36 \mathrm{mM}$ borate, 0.8 mM EDTA), $0.4 \times$ TBE running buffer, $6 \mathrm{~V} / \mathrm{cm}$ with linear ramped pulse times of 1-30 s, angle $120^{\circ}, 16^{\circ} \mathrm{C}$ buffer temperature, and $20 \mathrm{~h}$ running time. The insert sizes were determined using a BioDocAnalyzer video ducumentation system (Biometra, Göttingen, Germany). The MidRange PFG Marker II (New England Biolabs, Schwalbach/ Taunus, Germany) was used as marker for DNA size determination.

To generate more data in a shorter time, we run up to four gels at a time. After the first agarose gel is loaded, subsequent gels are placed carefully on top of the first one. Gels are kept together with two thin pipet tips at the front edge, as shown in Figure 1. It is important to be aware that the gels should lie exactly above each other and that the gels are completely covered with buffer.
Once the gels are stacked and covered with enough buffer, there is no difference between results achieved with one single or with multiple stacked gels. Figure 2 shows the results of a run with four stacked gels and NotI-digested BAC DNA. Thus, 120 samples can be separated in parallel using the standard Bio-Rad gels and 30well combs. Further increases in throughput may be achieved with custom-made combs that allow more samples per gel and with stacking even more gels on top of each other.

\section{REFERENCES}

1.Martins-Wess, F., R. Voß-Nemitz, C. Drögemüller, B. Brenig, and T. Leeb. 2002. Construction of a 1.2-Mb BAC/PAC contig of the porcine gene $R Y R 1$ region on SSC 6q1.2 and comparative analysis with HSA 19q13.13. Genomics 80:416-422.

2.Schwartz, D.C. and C.R. Cantor. 1984. Separation of yeast chromosome-sized DNAs by pulsed field gradient gel electrophoresis. Cell 37:67-75.

This study was supported by a grant of the German Research Council (DFG Le1032/7-1+2). Address correspondence to 
Dr. Tosso Leeb, Institute of Animal Breeding and Genetics, School of Veterinary Medicine Hannover, Bünteweg 17 p, 30559 Hannover, Germany.e-mail: tosso.leeb@ tiho-hannover.de

Received 13 December 2002; accepted 24 January 2003.

\section{Flávia Martins-Wess and Tosso Leeb}

School of Veterinary Medicine

Hannover, Hannover, Germany

\section{Background Priming during Reverse Transcription by Oligo(dT) Carried Over from mRNA Isolation}

BioTechniques 34:720-724 (April 2003)

The isolation of mRNA from total RNA is the first step in many experimental protocols such as the construction of cDNA libraries. Typically, mRNA isolation is accomplished using commercially available kits that provide some form of free or immobilized oligo(dT) to capture RNA with a poly(A) tail. The oligo(dT)/mRNA complex can be captured by different methods such as by streptavidin-biotin interaction on a magnetic particle or by physical retention on a cellulose matrix.

We observed that some of our plant mRNA preparations obtained using various mRNA isolation methods could be reverse-transcribed in the absence of any added primer. The yield and size distribution of the first-strand cDNA population synthesized without added primer were similar to that synthesized in the presence of added oligo(dT). Similar background priming was previously reported in total RNA preparations and attributed to the presence of small nucleolar RNAs that primed ran- domly (1). Likewise, efficient cDNA synthesis in the absence of oligo(dT) primer is thought to occur in mRNA preparations because of contamination with fragments of DNA or RNA that can bind to mRNA at random sites and serve as a primer, in which case, a reselection for poly(A) RNA is recommended (2).

In our experiments, however, isolating poly(A) RNA using two rounds of purification did not prevent first-strand synthesis in the absence of a primer. The size distribution of the first-strand cDNAs obtained from these experiments suggested that the endogenous priming was occurring at the $3^{\prime}$ end of the mRNA and not randomly. To demonstrate that the first-strand synthesis started from the poly(A) tail, we attempted to amplify two long fulllength cDNAs, the Arabidopsis thaliana ferredoxin-dependant glutamate synthase, (4947 bp, GenBank ${ }^{\circledR}$ accession no. Y09667) and the $A$. thaliana histone acetyltransferase 13 (5811 bp, GenBank accession no. AF510669), using an oligo(dT) primer in combination with a specific $5^{\prime}$-end primer. Both full-length cDNAs were successfully amplified by RT-PCR from the purified first-strand population generated without the addition of oligo(dT) primer (data not shown). This indicates that at least some background priming of cDNA had originated at the poly(A) tail.

A possible explanation for this background priming is the presence of exogenous oligo(dT) carried over from the mRNA isolation process. To test this hypothesis, we compared $A$. thaliana mRNA preparations from four different methods for the presence of oligo(dT).

In method $1,0.9 \mathrm{mg}$ total RNA and 400 pmol of a $5^{\prime}$-biotinylated oligonucleotide GAGAt $_{25}\left[\right.$ (gaga) ${ }_{3}$ ctc gag $t_{25}$ ] were mixed to a volume of $1.16 \mathrm{~mL}$ and then heat denatured at $65^{\circ} \mathrm{C}$ for 10 min. Thirty microliters of $20 \times$ SSC were added, and the mixture was left at room temperature for $30 \mathrm{~min}$. Streptavidin-magnetic particles $(150 \mu \mathrm{L}$ in $5 \times$ SSC; Roche Diagnostics, Laval, QC, Canada) were added, and the mixture was incubated for $10 \mathrm{~min}$ at room temperature before capturing the particles using a magnetic stand. The particles were washed three times with $1 \mathrm{~mL}$ $0.1 \times \mathrm{SSC}$, and the mRNA was eluted twice with $100 \mu \mathrm{L}$ water preheated to $65^{\circ} \mathrm{C}$.

In method 2, $0.2 \mathrm{mg}$ RNA and 150 pmol biotinylated oligo(dT) (Promega, Madison, WI, USA) in $0.5 \mathrm{~mL}$ water were heat-denatured at $65^{\circ} \mathrm{C}$ for 10 min. Thirteen microliters of $20 \times$ SSC were added, and the mixture was left at room temperature for $10 \mathrm{~min}$ before adding $0.6 \mathrm{~mL}$ in $5 \times \mathrm{SSC}$ streptavidinmagnetic particles and incubating at room temperature for $10 \mathrm{~min}$. The particles were captured and then washed four times with $0.3 \mathrm{~mL} 0.1 \times \mathrm{SSC}$, and the mRNA was eluted twice with 125 $\mu \mathrm{L}$ water preheated to $65^{\circ} \mathrm{C}$.

In method 3, $0.2 \mathrm{mg}$ total RNA in $200 \mu \mathrm{L}$ water was heat-denatured for 2 min at $65^{\circ} \mathrm{C}$ before being mixed with the equivalent of $400 \mu \mathrm{L}$ oligo $(\mathrm{dT})_{25^{-}}$ linked paramagnetic polymer particles (Dynal, Lake Success, NY, USA) that were concentrated to $200 \mu \mathrm{L}$ in $20 \mathrm{mM}$ Tris-HCl, pH 7.5, 1.0 M LiCl, 2 mM EDTA. The mixture was gently agitated for $5 \mathrm{~min}$ at room temperature. The particles were captured and washed twice with a buffer of $10 \mathrm{mM}$ Tris- $\mathrm{HCl}$, pH 7.5, 0.15 M LiCl, 1 mM EDTA before eluting the mRNA twice with 50 $\mu \mathrm{L}$ water preheated to $80^{\circ} \mathrm{C}$.

In method 4, $0.2 \mathrm{mg}$ RNA in $450 \mu \mathrm{L}$ water was heated for $5 \mathrm{~min}$ at $65^{\circ} \mathrm{C}$ and then mixed with $100 \mathrm{mg}$ oligo $(\mathrm{dT})_{25}$ cellulose (New England Biolabs, Mississauga, ON, Canada) and $50 \mu \mathrm{L} 5 \mathrm{M}$ $\mathrm{NaCl}$. After $5 \mathrm{~min}$ incubation at room temperature, the cellulose was pelleted, and the supernatant was heat-denatured and incubated again with the same cellulose for another cycle of selection. The cellulose was washed four times with $400 \mu \mathrm{L}$ wash buffer $(10 \mathrm{mM}$ Tris$\mathrm{HCl}, \mathrm{pH} 7.5,0.5 \mathrm{M} \mathrm{NaCl}, 1 \mathrm{mM}$ EDTA), once with $400 \mu \mathrm{L}$ low-salt buffer (10 mM Tris-HCl, pH 7.5, 0.1 M $\mathrm{NaCl}, 1 \mathrm{mM}$ EDTA), and the mRNA was eluted twice with $200 \mu \mathrm{L} 20 \mathrm{mM}$ Tris-HCl, pH 7.5, 1 mM EDTA, preheated to $70^{\circ} \mathrm{C}$.

The mRNA preparations obtained with the four different methods were used to carry out reverse transcription reactions with and without the addition of exogenous primer. First-strand cDNA was prepared from $50 \mathrm{ng}$ mRNA in $20 \mu \mathrm{L}$ volume using $100 \mathrm{U}$ 